Georgia State University

ScholarWorks @ Georgia State University

\title{
Teaching Behavioral Pain Management to Healthcare Professionals: A Systematic Review of Research in Training Programs
}

\author{
Jill E. MacLaren \\ Lindsey L. Cohen \\ Georgia State University, Ilcohen@gsu.edu
}

Follow this and additional works at: https://scholarworks.gsu.edu/psych_facpub

Part of the Psychology Commons

\section{Recommended Citation}

MacLaren, J. E., \& Cohen, L. L. (2005). Teaching behavioral pain management to healthcare professionals: A systematic review of research in training programs. The Journal of Pain, 6(8), 481-492. DOI: 10.1016/ j.jpain.2005.03.007

This Article is brought to you for free and open access by the Department of Psychology at ScholarWorks @ Georgia State University. It has been accepted for inclusion in Psychology Faculty Publications by an authorized administrator of ScholarWorks @ Georgia State University. For more information, please contact scholarworks@gsu.edu. 
Running head: TEACHING BEHAVIORAL PAIN MANAGEMENT

Teaching behavioral pain management to healthcare professionals: A systematic review of research in training programs

Jill E. MacLaren, M.A.

Department of Psychology, West Virginia University, Morgantown, WV 26506-6040

Lindsey L. Cohen, Ph.D.

Department of Psychology, Georgia State University, Atlanta, GA 30302-5010

Corresponding author: Lindsey L. Cohen, Ph.D., Department of Psychology, Georgia State University, Atlanta, GA 30302-5010, (phone) 404-651-1605, (fax) 404-651-1391, (email) LLCohen@GSU.Edu 


\begin{abstract}
Pain is a common and potentially debilitating condition. Whereas there is vast literature on developmentally appropriate behavioral techniques for pain management, results of curriculum evaluations and knowledge surveys reveal a dearth of awareness of these strategies in healthcare professionals. As a result, the development and evaluation of pain management training programs is an important endeavor. Results of studies evaluating such programs are promising and suggest that training may be an effective means of impacting healthcare professionals' knowledge, attitudes, and even patient care. These results must be interpreted with caution however, as the literature contains several conceptual and methodological limitations. These limitations, in combination with the wide diversity in program components, format of delivery, and research methods preclude definitive conclusions on the most practical and effective means to provide training. To address this question, further systematic work on the development and evaluation of pain management training programs is warranted.

Perspective: To address the problems of dissemination of behavioral pain management techniques the development and evaluation of pain management training programs is an important endeavor. The current article presents a systematic review of studies evaluating such programs and provides recommendations for future systematic work in this area.
\end{abstract}

Key words: Pain; training; non-pharmacological treatment; behavioral; education 
Teaching behavioral pain management to healthcare professionals: A systematic review of research in training programs

Pain is one of the most common complaints of patients seeking medical ${ }^{9}$ care with estimates of the prevalence of chronic pain ranging from $10 \%{ }^{6}$ to $50 \%^{13}$ of the general adult population. Disease-related pain is also common. Up to $95 \%$ of advanced stage cancer patients report experiencing pain $^{23}$ and pain prevalence in patients with acquired immune deficiency syndrome (AIDS) has been estimated at as high as $73 \% .{ }^{28}$ Unfortunately, pain is also a common condition in childhood. In a review conducted by Goodman and McGrath, ${ }^{22}$ prevalence estimates of recurrent abdominal pain in children ranged from $9.5 \%$ to $26.9 \%$. In the same review, prevalence estimates of migraine and back pain in children ranged $2.5 \%$ to $7.1 \%$ and $26 \%$ to $33 \%$ respectively.

Costs of pain

Regardless of etiology, it is indisputable that pain is a common and potentially debilitating condition. Although quantifying the "costs" of pain is difficult, research suggests that the condition can have direct effects on the individual and indirect effects on an individual's family, social networks, and society. With respects to impact on the individual, At the individual level, research has indicated that children who experience chronic or recurrent pain tend to have more school absences, ${ }^{55}$ lower perceived academic competence, ${ }^{58}$ and spend less leisure time with peers. ${ }^{35}$ Childhood pain has been linked with higher anxiety in adulthood, ${ }^{7}$ and adults with pain show higher rates of depression than those without pain. ${ }^{11}$ Pain has also been associated with impairments in family functioning. ${ }^{51}$ At a society level, costs due to lost productivity in the adult workforce have been estimated at over 62 billion dollars per year. ${ }^{54}$ 
Overview of pain management strategies.

Given the vast array of negative consequences of pain, the need for effective treatment is clear. As such, much research has been dedicated to the validation of pain management techniques. In general, these techniques are divided into pharmacological, physical, and behavioral categories.

Pharmacological and Physical strategies. Some of the oldest and most widely used pain management strategies are pharmacological and physical in nature. ${ }^{8}$ Common pharmacological treatments for pain include opioid and nonopioid analgesics, and local, regional, and general anesthetics. Although coverage of the mechanisms of action of drugs is beyond the scope of this paper, it is important to note that pharmacological strategies are generally considered to be an effective first line of treatment for pain. ${ }^{32}$ However, these treatments are not without side effects. For example, the use of opioid medications has been associated with risk of addiction, sedation, nausea, vomiting, constipation, and respiratory depression. ${ }^{44}$

In addition to pharmacological pain management interventions, several physical strategies have also received support. Commonly used techniques strategies include physical and occupational therapy techniques such as stretching and reconditioning, application of heat or cold, and transcutaneous electrical stimulation (TENS). Alternative physical interventions have also received recent empirical attention. For example, the use of massage ${ }^{24}$ and acupuncture ${ }^{14}$ have received empirical validation.

Behavioral strategies. A significant body of rResearch exists to supports the effectiveness of behavioral strategies in the treatment of pain. For example, dDistraction, has received a great deal of empirical support in the treatment of acute pain in children ${ }^{10,12 \text {, }}$ and adults. ${ }^{48}$ rRelaxation and imagery, ${ }^{2,56}$ hypnosis, ${ }^{25}$ and biofeedback ${ }^{40}$ have also received empirical support. Whereas 
most of the empirical support for these interventions has come from acute and procedural pain evaluations, they have also demonstrated efficacy in other types of pain (e.g., recurrent abdominal pain in children ${ }^{36}$ ). in the treatment of various patient populations and types of pain. In addition to single strategies, the efficacy of multicomponent behavioral interventions has also been demonstrated in several populations, including adults with chest pain, ${ }^{15}$ children with recurrent abdominal pain, ${ }^{50}$ and adults experiencing experimentally induced pain. ${ }^{41}$

Studies that have examined both behavioral and non-behavioral treatments have revealed several strengths of behavioral techniques. Results suggest that behavioral techniques alone can be as effective as pharmacological techniques for acute procedural pain. ${ }^{10}$ In addition, behavioral techniques used in conjunction with non-behavioral techniques have been found to be more effective than non-behavioral techniques alone for both acute ${ }^{33}$ and chronic pain. ${ }^{42}$ The use of combined interventions has been shown to be cost-effective, with patients receiving both behavioral and non-behavioral interventions requiring significantly fewer post-treatment followup medical visits. ${ }^{9}$ Behavioral intervention alone has also been shown to be effective in reducing sick leave in individuals with neck and back pain. ${ }^{38}$ Given the demonstrated clinical and cost effectiveness efficacy of behavioral strategies for pain management, it is important to include thethese techniques in comprehensive pain management treatment. importance of the inclusion of these techniques in patient care is clear.

\section{Professionals' knowledge of pain management}

Given the high prevalence and potential for functional impairment of pain, the necessity for adequate pain management is undisputable. Whereas there is an abundance of literature on appropriate techniques, it is unclear how much of this information has been translated into patient care. Education appears to be athe requisite step to ensure that this transition is made. 
Pain curriculum in health professionals' training. Despite the importance of the topic, there is a lack of pain management curricula in health professionals' training. This is especially the case with respect to behavioral techniques and children. For example, Zalon ${ }^{60}$ conducted a survey to evaluate the nature of pain management training provided to nursing students in associate and bachelor degree programs. Results indicated that a relatively small amount of the nursing curriculum was devoted to such training. Programs reported, on average, only 9.6 clock hours of instruction dedicated to pain. Surprisingly, a rather large proportion of this time was dedicated to the coverage of non-pharmacological techniques. Of these 9.6 hours, an average of only 2.9 hours (30\%) was devoted to coverage of such non-pharmacological techniques. Nonpharmacological strategies receiving coverage were both behavioral and non-behavioral in nature and included massage, application of heat or cold, relaxation, distraction, and imagery. Although some programs reported the use of both theoretical and practical information on these techniques, the vast majority of program respondents reported that these strategies were "just mentioned" (p. 264). Unfortunately, the authors did not provide an estimate of the total number of clock hours in nursing curricula reviewed. Without this information, the findings are difficult to interpret. It appears, however, that the coverage of pain in nursing curricula is not proportionate to the incidence of pain or the impairment caused by the condition.

Ferrell, Virani, Grat, VWallerand, and McCaffery ${ }^{17}$ conducted a content analysis of 50 of the most frequently used nursing textbooks and evaluated their coverage of pain-related material. Of the 45,683 pages reviewed, 249 included pain content. Results examining the coverage of non-pharmacological interventions were promising. Half of the textbooks provided such information, with a total of 61 pages dedicated to behavioral and physical interventions. Although this appears to be a relatively low figure, it is interesting that it almost doubles the 31 
pages dedicated to pharmacological interventions. The authors note that non-pharmacological strategies were presented in a positive manner, but that the level of detail provided on these strategies was inadequate to prepare nursing students to use them effectively. Again, no information on the amount of child-specific coverage was provided. Unfortunately, the scarcity of pain management training is not specific to the nursing field. Similar results were evidenced in studies examining a pain management curriculum in gerontology fellowship training, ${ }^{53}$ psychiatric residencies, ${ }^{37}$ and even anesthesiology residencies. ${ }^{29,45}$ To date, no study has evaluated child-specific pain curricula, but given the dearth of pain coverage in general, it is reasonable to assume that this information is also relatively sparse.

Pain management knowledge. Lack of inclusion of pain management in healthcare professionals' training is evidenced in surveys of their knowledge about these techniques. This is especially the case in knowledge of non-pharmacological techniques ${ }^{57}$ and techniques appropriate for children. Pederson, Matthies, and McDonald ${ }^{46}$ evaluated pain management knowledge in a sample of pediatric critical care nurses. In addition to inadequate understandings of analgesic medications for children, nurses in this study were not aware of the potential benefits of cognitive-behavioral treatments (e.g., modulation of pain signal transmission). As with gaps in curricula, impairments in pain management knowledge are not specific to the field of nursing. For example, Mortimer and Bartlett ${ }^{43}$ found that the majority of medical residents and fellows in their sample were unable to calculate correct doses of opioid medication for cancer patients. Taken together, results of curriculum evaluations and knowledge surveys demonstrate an overwhelming need for the education of healthcare professionals in the area of pain. Whereas all pain management topics are important, there seems to be an especially large gap in the need 
for further training in non-pharmacological (behavioral and physical) and developmentally appropriate techniques.

\section{Review of training in pain management}

Researchers have recognized the lack of training and corresponding lack of knowledge of pain management strategies in healthcare professionals. To address this inadequacy, several authors have developed and evaluated programs to teach pain management skills. Whereas the primary purpose of all of these programs is to provide training in pain management, there is wide diversity in both the depth and the breadth of information they include.

Evaluation and synthesis of studies examining training programs can offer insight into the most effective and practical means of providing information to healthcare professionals. Given that behavioral and developmentally appropriate techniques are effective and not widely communicated to healthcare professionals, the current review was conducted to begin to elucidate the most effective means of disseminating this type information. To provide a comprehensive review, training programs designed to teach behavioral pain management techniques, either alone or in combination with physical and pharmacological techniques, were evaluated. Unfortunately, only a few studies have evaluated pain management training programs providing child-specific information. Instead, most training programs teach generally applicable strategies (e.g., appropriate for both adults and children) and do not specify the population intended. Considering that the literature in child-specific programs is sparse, and knowledge gained from research pertaining to general (e.g., not child-specific) programs may be applicable to the development of child-specific programs, both general and child-specific training programs were reviewed. 
A literature review was conducted using computerized databases PsycINFO and MedLine with combinations of the search term 'pain' with the terms 'education', 'training', 'teaching', 'program', and 'curriculum'. In addition, reviews of the reference sections of relevant articles were conducted in order to identify additional studies meeting criteria. Criteria for inclusion in the review were: 1) the study evaluated an intervention designed primarily to teach pain management skills, 2) information was provided on the inclusion of behavioral strategies in the intervention, and 3) the study sample was healthcare professionals or future healthcare professionals (e.g., medical students). The literature search resulted in 12 studies that met these criteria. Studies were categorized based on the components included in the training program (i.e., behavioral only versus mixed behavioral and non-behavioral) as well as the target population of the strategies receiving coverage (i.e., general population versus child-specific). Tables 1 and 2 provide summaries of the training programs provided in each of these studies, including behavioral interventions receiving coverage. For greater detail on design, statistics used, outcome measures and results of studies see Tables 3 and 4 .

General bBehavioral training programs. Using these criteria, one three studiesy was were identified that examined a program designed to train professionals in behavioral techniques for general (i.e., not child-specific) pain management. Fisher, Nurse, and Kennedy ${ }^{19}$ evaluated a training program designed to teach behavioral principles and pain management strategies. General behavioral principles including conditioning theory, acquisition and extinction of behavior, and reinforcement and punishment were covered in the first seminar. Assessment of pain behavior was covered in the second seminar, and "goal setting and target achievement" (p. 285) was covered in the third seminar. Results indicated significant positive changes from pre- to post-training on an author-designed measure of nurses' knowledge of general behavioral 
principles (e.g., reinforcement and punishment) and attitudes toward disabled persons. Although not statistically tested, the authors report that when confronted with a patient complaining of unrelieved back pain after being medicated, nurses offered more adaptive responses (i.e., encouraging behavioral coping strategies) following the program than they did before the program. Although these results are promising, nurses' ability to identify specific “problem behaviors" that interfered with patient pain management on their unit remained unchanged from pre- to post-training. The authors did not provide an operational definition of "problem behaviors" however, making it difficult for the reader to interpret the meaning of these findings. For example, it is possible that the problem patient behaviors identified by nurses were in fact behaviors associated with unrelieved pain.

Two studies evaluated training in behavioral pain management techniques for children ${ }^{47}$, ${ }^{52}$. A study by Pederson ${ }^{47}$ revealed that nurses receiving training demonstrated more knowledge of and comfort using behavioral interventions than those not receiving such training. Finally, Solomon, Walco, Robinson, and Dampier ${ }^{52}$ showed that a training program could result in skill acquisition. Following a training program, $94 \%$ of healthcare professionals "attained high levels of skill” (p. 194), although the criteria upon which this classification was made was not specified.

General mMixed behavioral and non-behavioral training programs. Although behavioral pain management strategies are effective, few practitioners advocate for strictly behavioral management of pain. In this respect, programs that offer combinations of training in both behavioral and non-behavioral strategies (i.e., pharmacotherapy and/or physical therapy) have a distinct advantage, especially in the education of those individuals with relatively little experience in the care of patients with pain. Several studies were identified that evaluated 
programs teaching both behavioral and non-behavioral techniques for pain management in a general population.

Two studies ${ }^{31,59}$ evaluated the effects of training programs provided to students in the health care professions. Wilson et al. ${ }^{59}$ evidenced some positive changes in medical students' knowledge and attitudes about pain management, although results indicated no change in students' overall knowledge of the frequency of pain problems and no change in their perception of the clinical difficulty of treating pain patients. Jones ${ }^{31}$ examined the effect of a training program provided to emergency residents on patient outcomes. According to self-report, patients treated after the program achieved a greater amount of pain relief than patients treated before the program did. Further, although not tested statistically, more patients treated after the program reported clinically significant post-treatment reductions of pain than those that were treated before the program. Taken together, results of Jones ${ }^{31}$ and Wilson et al. ${ }^{59}$ suggest that pain management training programs result in positive effects. However, the generalizability of these studies is limited due to their inclusion of only students in their sample. It possible that changing behavior of established professionals is more difficult than that of students and the inclusion of practicing professionals in training program research is therefore important. Several studies were identified that addressed this issue.

Three studies evaluated changes in practicing nurses' knowledge and attitudes following the implementation of a training program. ${ }^{16,20,36}$ Variations in program content (e.g., hands-on experience versus didactic only), content coverage (number of behavioral strategies), and method of evaluation (knowledge and attitudes versus report of practice behavior) were evident across studies. However, results were generally consistent with improvements evidenced from pre- to post-program on all measures. In addition, all studies demonstrated that gains were maintained at 
follow-up evaluation. One study ${ }^{34}$ evaluated the effects of their program on post-surgical analgesia administration. Results were surprising, and revealed that children treated by nurses after the program waited significantly longer for their first dose of analgesics and received fewer doses of this medication than children treated before the program, it is unclear however, whether this delay was due to the implementation of behavioral techniques.

Although nurses are unquestionably important figures in the management of pain, many other healthcare professionals are involved in patient care. As such, inclusion of other disciplines in the evaluation of training programs is important. ThreeTwo studies evaluated effects of training programs on participants from various disciplines (e.g., physicians, nurses, psychologists, social workers). Breitbart, Rosenfeld, and $\mathrm{Passik}^{4}$ found positive attitude and knowledge changes following implementation of an ambitious, multicomponent program. Second, Brown ${ }^{5}$ reported on a system-wide attempt to improve pediatric pain management in adults and children in two rural hospitals. As with previous studies, following the program, improvements were evidenced on knowledge and attitudes, as were improvements in the documentation of pain by nurses and physicians. Further, there was more documented use of non-pharmacological pain management techniques following the program than before the program. Notably, of the nonpharmacological strategies covered in this program (e.g., healing touch, acupuncture, reflexology), only one, meditation, was behavioral in nature. Results of Zaza and Sellick ${ }^{61}$ were less encouraging and found that most of those professionals who participated in their programs felt that the sessions had no effect on their perceptions or planned use of the strategies. However, some positive effects were evidenced in this study, with professionals perceiving behavioral strategies to be more efficacious post-program than they had pre-program. 
Child-specific training programs. Given that strategies for pain management for children can be qualitatively different from those for adults, ${ }^{18}$ provision of child-specific training is important. Unfortunately, little research has examined such training. In fact, only four studies that included information on child-specific interventions were identified, and they were widely diverse in both the depth and breadth of their child-specific coverage.

Brown ${ }^{5}$ reported on a system-wide attempt to improve pain management in adults and children in two rural hospitals. As with previous studies, following the program, improvements were evidenced on knowledge and attitudes, as were improvements in the documentation of pain by nurses and physicians. Further, there was more documented use of non-pharmacological pain management techniques following the program than before the program.

The remaining three studies evaluated programs that provided only child-specific training in pain management. Knoblauch and Wilson ${ }^{34}$ demonstrated effects of their program on postsurgical analgesia administration. Results were surprising, and revealed that children treated after the program waited significantly longer for their first dose of analgesics and received fewer doses of this medication than children treated before the program, it is unclear however, whether this delay was due to the implementation of behavioral techniques. A study by Pederson ${ }^{47}$ revealed that nurses receiving training demonstrated more knowledge of and comfort using behavioral interventions than those not receiving such training. Finally, Solomon, Walco, Robinson, and Dampier ${ }^{52}$ showed that a training program could result in skill acquisition. Following a training program, $94 \%$ of healthcare professionals "attained high levels of skill” (p. 194), although the criteria upon which this classification was made was not specified.

Taken together, these studies are promising in that they suggest that training programs may be an effective means of impacting patient pain management. These results must be 
interpreted with caution however, as the literature contains several conceptual and methodological limitations. Some of these limitations are specific to the nature of the training programs (e.g., components included, developmental considerations), and others are more procedural in nature (e.g., use of statistics, inclusion of control groups).

Critique of pain management training research: Program considerations.

Program description. Summaries and conclusions based on the previously discussed research must consider the methodological and conceptual limitations in this body of literature. One limitation is the lack of detailed descriptions provided by the authors of the format and content of the programs. As is evident from Tables 1 and 2, author-provided descriptions of training program formats were vague. Many authors simply stated that a "workshop" or "seminar" was used. More information on how techniques were presented to participants is warranted. Was evidence supporting the strategies presented? Were role-plays or other forms of practice used? Were questions from participants addressed? Solomon and colleagues ${ }^{52}$ provided one of the best descriptions. These authors included a section detailing the progression of participants throughout the program (e.g,, being introduced to one another, hearing a lecture, experiencing a relaxation and imagery session, receiving materials). This information is valuable for those who wish to replicate these studies, but unfortunately this level of detail is not included by most authors.

In addition, most studies provided little description of the components included in their training programs. Of most concern are the several studies that simply state "nonpharmacological" 35,34 or "psychological"4 interventions received coverage. In line with their detailed description of the form of their program, Solomon and colleagues ${ }^{52}$ reported on the use of a manualized training protocol for their program. A detailed list of topics, including amount of 
time devoted to each, was provided by Ferrell and colleagues; ${ }^{16}$ and Wilson and colleagues ${ }^{59}$ reported the use of written, didactic "modules" that were written by course instructors to address 35 specific learning objectives. Although further discussion of these objectives was not provided in the article, the indication that information was shared based on a set of formal guidelines is promising. Although space restrictions in journal publications likely contribute to the absence of this type of information in other articles, its inclusion is especially important in order to allow future research to replicate the findings.

Basis for inclusion of components. Compounding the lack of program description is the relative absence of justification for which pain management techniques were included.

Knoblauch and Wilson ${ }^{34}$ stated that their program was based on recommendations provided by the Agency for Healthcare Policy and Research, but did not include further discussion. Only three studies offered empirical data to support their programs. ${ }^{46,20,52}$ This lack of justification is especially concerning as some of the interventions included in these programs have not received empirical support. For example, Jones ${ }^{31}$ offered information on three behavioral strategies: room atmosphere, music, and positive reassurance. Although little information was offered as to the nature of the coverage of these interventions, positive reassurance has been found to correlate with increased patient pain and distress during acute medical procedures., 21, 39

Critique of pain management training research: Methodological considerations.

Multiple-component interventions. In addition to program-relevant concerns, research in pain management training is also limited by several methodological considerations. Although many training programs appeared to demonstrate positive effects on characteristics of interest (e.g., knowledge of pain management strategies), interpretation of the mechanisms responsible for these results is limited by the multiple component nature of the interventions. All of the 
studies evaluated training programs that contained coverage of several pain management strategies. These strategies might all have been behavioral (e.g., distraction and relaxation) or might have been a combination of behavioral and non-behavioral techniques (e.g., biofeedback and pharmacological interventions). Although there is no question that the treatment of pain is complex and usually requires multiple interventions, the nature of these studies presents problems in the interpretation of results. Without dismantling research it is impossible for the reader to assess whether all of the program components were necessary to produce changes in outcome measures.

Along similar lines, the optimal means of delivering pain management training is also difficult to assess on the basis of these studies. Training programs varied in length, ranging from two hours ${ }^{46}$ to two weeks, ${ }^{4}$ and in format, with some including only didactic ${ }^{31}$ and others experiential $^{52}$ components. Only one study attempted to examine differences based on the format in which their training was delivered. ${ }^{36}$ The three-group design used in this study allowed authors to make comparisons between no education, a training program consisting of didactic information only, and a training program consisting of both didactic information and hands-on experience. Although this study is a step in the right direction, the coverage of multiple strategies in the didactic component still leaves the reader with questions as to the efficacy of each. Gaining an understanding of the optimal content and format of training programs is important to allow implementation in the most efficient and cost effective manner. If a training program delivered in a one-hour didactic seminar is equally effective as a longer, more involved seminar, the former would be preferable for practical reasons.

Outcome measures. The nature of the outcome measures used in these studies also presents potential problems. For example, most studies evaluated their programs using changes 
in participants' self-reported knowledge and attitudes. In most cases, the measures used to assess these variables were author-designed and no psychometric analyses were reported. In fact, only one study ${ }^{36}$ reported on the psychometric properties of their measure. These authors reported adequate Chronbach's alpha values, representing the internal consistency of their measure. Evaluation of the psychometric properties of assessment instruments in other studies is imperative to allow the readers to draw conclusions on the validity of the measures. ${ }^{26}$

In addition to the lack of information regarding the psychometrics of assessment measures, most studies fail to consider the potential impact of practice effects on their results. All studies reviewed used comparisons of pre-training and post-training scores on variables of interest, and in most cases the same assessment measure was administered at both time points. In fact, Fisher and colleagues ${ }^{19}$ were the only authors to use parallel forms of their knowledge questionnaire from pre- to post-program. Multiple administrations of the same measure results in difficulties, as it is possible that changes in scores were due to the completion of a measure multiple times, rather than actual changes in the variables of interest. In addition, exposure to items on a pre-program questionnaire may have cued participants to pay more attention to information that is relevant to these items during training. If this was indeed the case, responses on post-program versions of these measures may not have been a valid assessment of the breadth of knowledge gained by participants.

The exclusive use of self-report measures by most of these studies is also problematic. Although self-report offers valuable data, this means of evaluation is problematic as participants can manipulate their responses in reaction to demand characteristics. This is especially the case in studies that assessed participants' attitudes toward pain management in which more positive responses were clearly more desirable. ${ }^{36}$ Unfortunately, only four studies used outcome measures 
other than self-report. Solomon and colleagues ${ }^{52}$ were the only authors to conduct direct observations of participants' skills in administering behavioral pain management strategies. Although results of this study demonstrated that participants could indeed implement the strategies taught, it is important to note that the behavioral observations were conducted in an experimenter designed and administered setting. This procedure limited the generalizability of these results to actual clinical care. Three studies ${ }^{31,5,34}$ used patient-care indicators (e.g., patient pain reports, administration of analgesia) instead of participant reports or performance to assess program success. Although these studies hold promise because they demonstrate that training can impact patient care, none collected self-reports from program participants. Collecting both forms of assessment would have allowed the authors to examine the relations among changes in participants' self-reported knowledge and attitudes and changes in patient care.

Inclusion of control groups. In addition to problematic outcome measures, the failure to include control groups in most training research limits the internal validity of these studies. Although many studies evidenced improvements in variables of interest from pre-program to post-program assessment, the lack of control groups limits the ability to conclude that these changes were due to implementation of the program. It is possible instead that the passage of time or some other potential confounding factor was responsible for the results. Three studies should be recognized for their use of a control group. ${ }^{20,36,47}$ In particular, the study by Lasch and colleagues is especially strong because it included both a non-treatment and a didactic only treatment control. Results of these studies should still be viewed with caution however, as none of the authors reported on how participants were assigned to treatment or control groups. Without random assignment to groups, the validity of differences found between control and treatment participants may be questionable. 
Use of statistics. In line with the importance of control groups, the use of formal statistical procedures is necessary to allow accurate interpretations of differences in scores from pre- to post-assessment. Statistics are used to evaluate differences in scores and allow researchers to draw conclusions about the relative likelihood that results are due to the implementation of interventions, rather than simply due to chance. It is encouraging that most studies included some formal statistical evaluation of their results (e.g., analysis of variance, $t$-tests). Although most of these studies report their statistics correctly, several ${ }^{59,36,5}$ provide only a $p$ value without the inclusion of a corresponding value for the statistic of interest (e.g., $F$ or $t$ value). Although a $p$ value allows for evaluation of the statistical significance of the effect, the lack of statistical values prohibits the comparison of these authors' results to other published research. Even more problematic arewas the two one studiesy ${ }^{16,52}$ that report only descriptive data on changes in variables of interest with no effort to confirm that these changes were statistically significant.

Follow-up data. In addition to evaluating the efficacy of training programs in the production of immediate effects, it is important to assess the durability of these effects over time. In this case the use of follow-up evaluation is warranted. Unfortunately, few studies included follow-up evaluations of their procedures, and of these still fewer considered attrition rates. For example, Lasch and colleagues ${ }^{36}$ and Zaza and Sellick ${ }^{61}$ reported favorable results on follow-up data at one year and three months respectively. Neither reported the number of original participants who completed follow-up however, limiting the interpretation of these results.

Unfortunately, the one study that provided this information ${ }^{59}$ had low response rates, with only $41 \%$ of the original sample completing follow-up measures. Attrition is potentially problematic because it can result in a lack of representativeness of participants who completed follow-ups. It 
is possible, for example, that those participants who were impacted most positively by the programs were those who responded to follow-up evaluations.

Sample characteristics. The final considerations in training program research are related to sample characteristics. Ideally, a sample in any research study should be randomly drawn from the population of interest. Failure to do so places limits on the generalizability (i.e., external validity) of study results. Unfortunately, in practice such sampling procedures are difficult and rarely feasible. Such is the case in pain management training research. Many of the studies ${ }^{34}$ relied on convenience sampling procedures, rather than randomly selected participants. In the cases in which random sampling was not used, it is important that authors provide detailed data on sample characteristics (e.g., number of years in practice, past training in pain management). Again, this type of data was not provided in most of the studies. For example, Fisher et al. ${ }^{19}$ reported that 13 nurses participated in their training program, but did not provide information on how these nurses were selected, nor did they provide information of the demographic or clinical characteristics of their sample. Without this information, it is difficult to draw conclusions on the degree to which these nurses are representative of a general population of nurses.

Another consideration in the evaluation of training research is sample size. In this respect many of the studies are strengthened by their inclusion of fairly large samples. For example, Lasch and colleagues ${ }^{36}$ included over 400 nurses and Breitbart and coauthors ${ }^{4}$ sampled 152 healthcare professionals. The use of smaller sample sizes in several other studies result in potential problems, however. Fisher and colleagues ${ }^{19}$ and Ferrell and colleagues ${ }^{16}$ included only 13 and 26 nurses respectively. Small sample sizes are concerning for several reasons. First, inclusion of a small number of participants increases the likelihood of making a Type II error. Second, small sample size limits the ability to generalize results to the general population. Using 
larger sample sizes increases the likelihood that the participants included are representative of the population as a whole.

Along similar lines, it is important to note that there are many populations involved in the management of patients with pain. Nurses, physicians, psychologists, as well as a host of other professions often find themselves confronted with patients in pain. Each of these professions has unique background and training needs. As such, pain management training programs should target each of these specialties. The studies reviewed varied on the number of professions (e.g., nurses only versus range of healthcare professionals) and level of education (e.g., practicing professionals versus students) included in their sample. Each type of study has its own strengths and weaknesses. For example, inclusion of only nurses increases the internal validity of the study, but limits the generalizability of the results to other healthcare professions. Inclusion of multiple professions has the opposite problem as results may not be as internally valid, but are likely more generalizable to a larger population.

Overall Conclusions and Future Directions.

Unfortunately, pain is a common and potentially disabling condition. Costs of pain are evidenced at many levels including individual, familial, and societal effects. As such, effective management of pain is an important endeavor. Although there is a reasonable body of literature providing information on effective pain management techniques, research indicates that this information has not been translated to healthcare professional training. ${ }^{17}$ Subsequently, healthcare professionals exhibit little knowledge of effective interventions, especially with respect to behavioral techniques and techniques that are developmentally. ${ }^{49}$ Based on these findings, there is a clear need to provide further training in order to maximize the successful treatment of pain. 
Although conceptual and methodological considerations limit conclusions on the basis of these studies, research evaluating pain management training reveals several promising results. First, it appears that training in behavioral pain management techniques, either alone or in combination with non-behavioral techniques, may be an effective means of changing healthcare professionals' attitudes, knowledge level, and possibly clinical practices. In addition, such changes have been evidenced in both students and practicing healthcare professionals, as well as in several different disciplines. Furthermore, both general and child-specific programs have resulted in positive effects, and some of these effects have been durable over time. Finally, it is promising that some of these effects have demonstrated durability over time.

Now that research has supported the efficacy of training programs in general, more systematic work is warranted to elucidate the most efficient means of providing education. First and foremost, there is a need to develop standards upon which these programs are evaluated. Outcome measures in the current studies ranged from knowledge and attitudes of pain management strategies to patient care indicators. Even in the cases in which one construct was assessed, there was diversity in its definition. For example, "knowledge" was assessed in many studies, but there was little consensus on the definition of "knowledge." Some studies included ability to report on pain statistics (e.g., prevalence of pain complaints) in their evaluation of knowledge, whereas others did not. In addition, some studies required knowledge of assessment strategies in addition to treatment techniques whereas others did not. In order to effectively synthesize results, future research should use consistent outcomes to evaluate success.

In addition to the generation of evaluation criteria, the development of training programs should also be conducted in a more systematic manner. Currently, most studies appear to have generated their programs in isolation. To this point, little attempt has been made to build on prior 
research in pain management training and many programs do not include the most well validated pain management strategies. Future work should make an effort to build upon previous research by including pain management strategies that have received empirical support. Furthermore, the evaluation of existing training programs with new populations and in new settings is warranted.

Because pain management is a complex problem, it is likely that several outcomes will be important. At this point, there is a necessity to go beyond demonstrating effects on knowledge and attitudes to demonstrating changes in medical practice. Future research should focus on the evaluation of clinician's ability to implement the strategies taught during these programs as well as their actual implementation of these strategies upon their return to practice. Further, it is important to note that the ultimate measure of the effectiveness of any pain management training program is better patient outcomes. Such outcomes, including patient-reported pain management and quality of life indices, should be reflected in future research. Although a few studies have attempted to address this issue, further work is warranted. Indeed, work in the social psychology literature suggests that self-reported attitudes correspond to overt behavior only to a very limited extent. ${ }^{1,30}$ Despite the fact that many of these studies demonstrate changes in attitudes, behavior change may require more than simple education strategies. For example, Heye and Goddard ${ }^{27}$ outline additional components that they feel are necessary to include in training programs in order to change practice. These components include assessment of learned potential inhibitors (beliefs and experiences) in both professionals and patients.

As the efficacy of training programs is established, dismantling research becomes increasingly important. To elucidate the most effective and practical way of affecting outcomes, future research should evaluate the amount and nature of training needed to produce lasting effects. Important variables to assess are the ideal length of a training protocol and the necessity 
of inclusion of experiential components. Additionally, the relative importance of individual components should be evaluated. In terms of specific components, further attention should be paid to the inclusion of coverage of behavioral techniques and techniques appropriate to children. Currently, few studies focus on the provision of information on effective behavioral techniques, despite evidence that knowledge in this area is lacking. Additionally, authors should be aware of child-specific pain management strategies and should incorporate them in development and evaluation of their training programs. The inclusion of control groups will be important as this area progresses. Specifically, systematic research should include comparisons of specialized education programs in behavioral pain management to no education and to general education about pain and pain management.

In sum, pain is a common and potentially debilitating condition. Although several effective and developmentally appropriate behavioral techniques for pain management exist, results of curriculum evaluations and knowledge surveys reveal a dearth of awareness of these strategies in healthcare professionals. As a result, the development and evaluation of pain management training programs is an important endeavor. Although research thus far has revealed several potential benefits of such programs, further systematic work is warranted to determine the most practical and effective way to deliver training. Specifically, future research should provide training programs with empirically supported components and should be careful to include detailed descriptions of the means by which training is delivered. Evaluations of training programs should be on the basis of improved patient outcomes and demonstrated clinical behavior in addition to knowledge and attitudes and should make use of stringent research techniques (e.g., randomized controlled trials). 
Author Note

This article is based on the preliminary exam paper of the first author under the direction of the second, at West Virginia University. The authors would like to thank Kevin Larkin, PhD and Tracy Morris, $\mathrm{PhD}$ for their comments on an earlier version of this manuscript. 


\section{References}

1. Ajzen I. Attitudes, personality, and behavior. Chicago: Dorsey, 1998.

2. Ball TM, Shapiro DE, Monheim CJ, Weydert JA. A pilot study of the use of guided imagery for the treatment of recurrent abdominal pain in children. Clin Pediatr 2003; 42; 527 532 .

3. Blount RL, Sturges JW, Powers SW. Analysis of child and adult behavioral variations by phase of medical procedure. Behav Ther 1990; 21; 33-48.

4. Breitbart W, Rosenfeld B, Passik, SD. The Network Project: A multidisciplinary cancer education and training program in pain management, rehabilitation, and psychosocial issues. $\mathrm{J}$ Pain Symptom Manageme 1998; 15; 18-26.

5 . Brown ST. Outcomes analysis of a pain management project for two rural hospitals. J Nurs Care Quality 2000; 14; 28-34.

6. Buskila D, Abramov G, Biton A, Neumann L. The prevalence of pain complaints in a general population in Israel and its implications for utilization of health services. J Rheumatol 2000; 27; 1521-1525.

7. Campo JV, DiLorenzo C, Chiappeta L, Bridge J, Colborn DK, Gartner JC. et al. Adult outcomes of pediatric recurrent abdominal pain: Do they just grow out of it? Pediatr 2001; 108; E1.

8. Caraceni A., Cheville A., Portenoy R.K. Pain management: Pharmacological and nonpharmacological treatments. In Massie MJ, ed. Pain: What psychiatrists need to know, Washington: American Psychiatric Association, 2000: 23-88.

9. Cipher DJ, Fernandez E, Clifford PA. Cost-effectiveness and healthcare utilization in a multidisciplinary pain center: Comparison of three treatment groups. J Clin Psychol Med Settings 2001; 8; 237-344.

10. Cohen LL, Blount RL, Cohen RJ, Schaen ER, Zaff JF. Comparative study of distraction versus topical anesthesia for pediatric pain management during immunizations. Health Psychol 1999; 18; 591-598.

11. Currie SR. Wang J. Chronic back pain and major depression in the general Canadian population. Pain 2004; 107; 54-60.

12. Dahlquist LM, Pendley JS, Landthrip DS, Jones CL, Steuber CP. Distraction interventions for preschoolers undergoing intramuscular injections and subcutaneous port access. Health Psychol 2002; 21; 94-99.

13. Elliot AM, Smith BH, Penny KI, Smith WC, Chambers WA. The epidemiology of chronic pain in the community. Lancet $1999 ; 354 ; 1248-1252$.

14. Eshkevari L. Acupuncture and pain: A review of the literature. Amer Assoc Nurs Anesthetists J 2003; 71; 361-370.

15. Esler JL, Barlow DH, Woolard RH, Nicholson RA, Nash JM, Erogul, MH. A briefcognitive behavioral intervention for patients with noncardiac chest pain. Behav Ther 2003; 34; 129-148.

16. Ferrell BR, Grant M, Ritchey KJ, Ropchan R, Rivera, LM. The pain resource nurse training program: A unique approach to pain management. J Pain Symptom Manage 1993; 8; 549-556.

17. Ferrell BR, Virani R, Grant M, Vallerand, McCaffery M. Analysis of pain content in nursing textbooks. J Pain Symptom Manage 2000; 19; 216-228. 
18. Finley GA, McGrath PJ. Introduction: The roles of measurement in pain management and research. In Finley GA, McGrath PJ, eds. Measurement of pain in infants and children. Seattle, WA: IASP, 1998: 1-4.

19. Fisher K, Nurse M, Kennedy P. Teaching nurses behavioral methods for pain management: A pilot study. Behav Psychother 1989; 17; 283-289.

20. Francke AL, Luiken JB, Garssen B, Abu-saad HH, Grypdonck M. Effects of a pain programme on nurses' psychosocial, physical, and relaxation interventions. Patient Educ Counsel 1996; 28; 221-230.

21. Gonzalez JC, Routh DK, Armstrong FD. Effects of maternal distraction versus reassurance on children's reactions to injections. J Pediatr Psychol 1993; 18; 593-604.

22. Goodman JE, McGrath PJ. The epidemiology of pain in children and adolescents: A review. Pain 1991; 46; 247-264.

23. Grond S, Zech D, Diefenbach C, Bischoff, A. Prevalence and pattern of symptoms in patients with cancer pain: A prospective evaluation of 1635 cancer patients referred to a pain clinic. J Pain Symptom Manage 1994; 9; 372-382.

24. Hasson D, Arnetz B, Jelveus L, Edelstam B. A randomized clinical trial of the treatment effects of massage compared to relaxation tape recordings on diffuse long-term pain. Psychother Psychosom 2004; 73; 17-24.

25. Hawkins RM. A systematic meta-review of hypnosis as an empirically supported treatment for pain. Pain Rev 2001; 8; 47-73.

26. Haynes SN. O'Brien WH. Principles and practice of behavioral assessment. New York: Kluwer Academic/Plenum, 2000.

27. Heye ML, Goddard L. Teaching pain management: How to make it work. J Nurs Staff Dev $1999 ; 15 ; 27-36$.

28. Hirschfeld S. Pain as a complication of HIV disease. AIDS Patient Care STDs, 1998; $12 ; 91-108$.

29. Huggins LJ, Ward SP, Stannard CF. Provision of training in chronic pain management for specialist registrars in the United Kingdom. Anaesthesia 1999; 54; 761-768.

30. Jaccard J., Hilbig DW, Wan CK, Gutman M, Kritz-Silversein DS. Individual differences in attitude-behavior consistency: The prediction of contraceptive behavior. J Appl Social Psychol $1990 ; 49 ; 211-218$.

31. Jones JB. Assessment of pain management skills in emergency medicine residents: The role of a pain education program. J Emerg Med 1999; 17; 349-354.

32. Julien RM. A primer of drug action. New York: Henry Holt, 2001.

33. Kazak AE, Penati B, Boyer BA, Himelstein B, Brophy P, Waibel MK, et al. A randomized controlled prospective outcome study of a psychological and pharmacological intervention protocol for procedural distress in pediatric leukemia. J Pediatr Psychol 1996; 21; 615-631.

34. Knoblauch SC, Wilson CJ. Clinical outcomes of educating nurses about pediatric pain management. Outcomes Manage Nurs Prac 1999; 3; 87-89.

35. Langeveld JH, Koot HM, Passchier J. Headache intensity and quality of life in adolescents: How are changes in headache intensity in adolescents related to changes in quality of life? Headache 1997; 37; 37-42.

36. Lasch KE, Wilkes G, Lee J, Blanchard R. Is hands-on experience more effective than didactic workshops in postgraduate cancer pain education? J Cancer Educ 2000; 15; 218-222. 
37. Leo RJ, Pristach CA, Streltzer J. Incorporating pain management training into the psychiatry residency curriculum. Acad Psychiatry 2003; 27; 1-11.

38. Linton SJ. A cognitive-behavioral group intervention as prevention for persistent neck and back pain in a non-patient population: A randomized controlled trial. Pain 2001; 90; 83-90.

39. Manimala M, Blount RL, Cohen LL. The Influence of parental reassurance and distraction on children's reactions to an aversive medical procedure. Child Health Care 2000; 29; 161-177.

40. Middaugh SJ, Pawlick K. Biofeedback and behavioral treatment of persistent pain in the older adult: A review and a study. Appl Psychophysiol Biofeedback 2002; 27; 185-202.

41. Milling LS, Kirsch I, Meunier SA, Levine MR. Hypnotic analgesia and stress inoculation training: Individual and combined effects in analog treatment of experimental pain. Cogn Ther Res 2002; 26; 355-371.

42. Morley S, Eccelston C Williams, A. Systematic review and meta-analysis of randomized controlled trials of cognitive behavioral therapy and behavior therapy for chronic pain in adults, excluding headache. Pain 1999; 80; 1-13.

43. Mortimer JE. Bartlett NL. Assessment of knowledge about cancer pain management by physicians in training. J Pain Symptom Manage 1997; 14; 21-27.

44. O’Mahony S, Coyle N, Payne R. Current management of opioid-related side effects. Oncol 2001; 15; 61-73.

45. Parris MR, Warner JA, Clark C. Chronic pain management training for senior registrars in anaesthesia. Anaesthesia 1992; 47; 804-806.

46. Pederson C, Matthies D, McDonald S. A survey of pediatric critical care nurses' knowledge of pain management. Am J Crit Care 1997; 6; 289-295.

47. Pederson C. Non-pharmacological interventions to manage children's pain: Immediate and short-term effects of a continuing education program. J Contin Educ Nurs 1996; 27; 131 140 .

48. Petrovic P, Petersson PH, Ghatan S, Stone-Elander MI. Pain-related cerebral activation is altered by a distracting cognitive task. Pain 2000; $85 ; 19-30$.

49. Salantera S, Lauri S, Salmi TT, Helenius H. Nurses' knowledge about pharmacological and non-pharmacological pain management in children. J Pain Symptom Manage 1999; 18; 289299.

50. Sanders MR, Herston A, Shepherd RW, Cleghorn G, Woolford H. The treatment of recurrent abdominal pain in children: A controlled comparison of cognitive-behavioral family intervention and standard pediatric care. J Consult Clin Psychol 1994; 62; 306-314.

51. Schanberg LE, Keefe FJ, Lefebvre JC, Kredisch DW, \& Gil KM. Social context of pain in children with Juvenile Primary Fibromyalgia Syndrome: Parental pain history and family environment. Clin J Pain 1998; 14; 107-115.

52. Solomon R, Walco GA, Robinson MR, Dampier CD. Pediatric pain management: Program description and preliminary evaluation results of a professional course. J Dev Behav Pediatr 1998; 19; 193-195.

53. Stein, WM. Ferrell BA. Pain management in geriatric fellowship training. Gerontol Geriatr Educ 1999; 20; 69-78.

54. Stewart WF, Ricci JA, Chee E, Morganstein D, Lipton R. Lost productive time and cost due to common pain conditions in the US workforce. JAMA 2003; 290; 2443-2457.

55. Sturge C, Garralda ME, Boissin M, Doore CJ Woo, P. School attendance and juvenile chronic arthritis. Br J Rheumatol 1997; 26; 1218-1223. 
56. Syrjala KL, Donaldson GW, Davis MW, Kippes ME. Relaxation and imagery and cognitive-behavioral training reduce pain during cancer treatment: A controlled clinical trial. Pain 1995; 63; 189-198.

57. Titler MG, Rakel BA. Nonpharmacologic treatment of pain. Crit Care Nurs Clinics North America 2001; 13; 221-232.

58. Walker LS, Guite JW, Duke M, Barnard JA, \& Greene JW. Recurrent abdominal pain: A potential precursor of irritable bowel syndrome in adolescents and young adults. Journal of Pediatr 1998; 132; 1010-1015.

59. Wilson JF, Brockopp GW, Kryst S, Sterger H, Witt WO. Medical students' attitudes toward pain before and after a brief course on pain. Pain 1992; 50; 251-256.

60. Zalon ML. Pain management instruction in nursing curricula. J Nurs Educ 1995; 34; 262-267.

61. Zaza C, Sellick S. Assessing the impact of evidence-based continuing education on nonpharmacological management of cancer pain. J Cancer Educ 1999; 14; 164-167. 
Table 1

Summary of pain management training programs

\begin{tabular}{|c|c|c|c|c|}
\hline First Author & Length & Type of Pain & Behavioral Techniques & Program Details \\
\hline Fisher & $\begin{array}{l}3 \text { half-day } \\
\text { seminars }\end{array}$ & Unspecified & $\begin{array}{l}\text { Conditioning theory, acquisition and } \\
\text { extinction of behavior, and } \\
\text { reinforcement and punishment. }\end{array}$ & $\begin{array}{l}\text { Each seminar was divided into two halves; the first half was } \\
\text { in lecture format and the second half was in workshop } \\
\text { format. }\end{array}$ \\
\hline Solomon & 16 hours & Procedural & $\begin{array}{l}\text { Deep breathing, relaxation, mental } \\
\text { imagery. Strategies to increase } \\
\text { children's use of these techniques } \\
\text { (e.g., rapport building in an age- } \\
\text { appropriate manner, collecting } \\
\text { information on children's past } \\
\text { experiences with procedures, and } \\
\text { coaching children through the } \\
\text { procedure). }\end{array}$ & Seminar including didactic and experiential components \\
\hline Pederson & 2 hours & Unspecified & $\begin{array}{l}\text { Deep breathing, relaxation, } \\
\text { distraction, imagery, cognitive } \\
\text { restructuring }\end{array}$ & $\begin{array}{l}\text { Lectures, videotaped modeling, discussion, and skill } \\
\text { practice in response to case vignettes. Provision of } \\
\text { distraction stimuli (e.g., bubbles) for participant use upon } \\
\text { return to their unit. }\end{array}$ \\
\hline Wilson & 6 hours & $\begin{array}{l}\text { Acute, Chronic, } \\
\text { Cancer-related }\end{array}$ & $\begin{array}{l}\text { Biofeedback, progressive muscle } \\
\text { relaxation }\end{array}$ & $\begin{array}{l}\text { Lecture, demonstration, attendance at grand rounds and } \\
\text { case-management conferences }\end{array}$ \\
\hline Jones & 4 hours & Acute & $\begin{array}{l}\text { Environmental manipulation, positive } \\
\text { reassurance, music }\end{array}$ & Lecture and quiz \\
\hline
\end{tabular}

(table continues) 
Table 1 (continued)

\begin{tabular}{lllll}
\hline First Author & Length & Type of Pain & Behavioral Techniques & Program Details \\
\hline Lasch & 1 day & Cancer-related & Relaxation, music & $\begin{array}{l}\text { Group 1: Workshop } \\
\text { Group 2: Workshop plus shadowing a pain nurse specialist }\end{array}$ \\
Ferrell & 40 hours & Unspecified & Relaxation, distraction, imagery & Lecture, homework assignments, clinical practice sessions \\
Francke & 24 hours & Post-operative & $\begin{array}{l}\text { Giving information, emotional } \\
\text { support, promotion of autonomy, } \\
\text { relaxation, distraction, modification } \\
\text { of environment }\end{array}$ & $\begin{array}{l}\text { Lecture and discussion in small groups, audiovisual } \\
\text { presentations, practical exercises, provision of relevant }\end{array}$ \\
literature
\end{tabular}


Table 2

Summary of outcome measures and results of studies

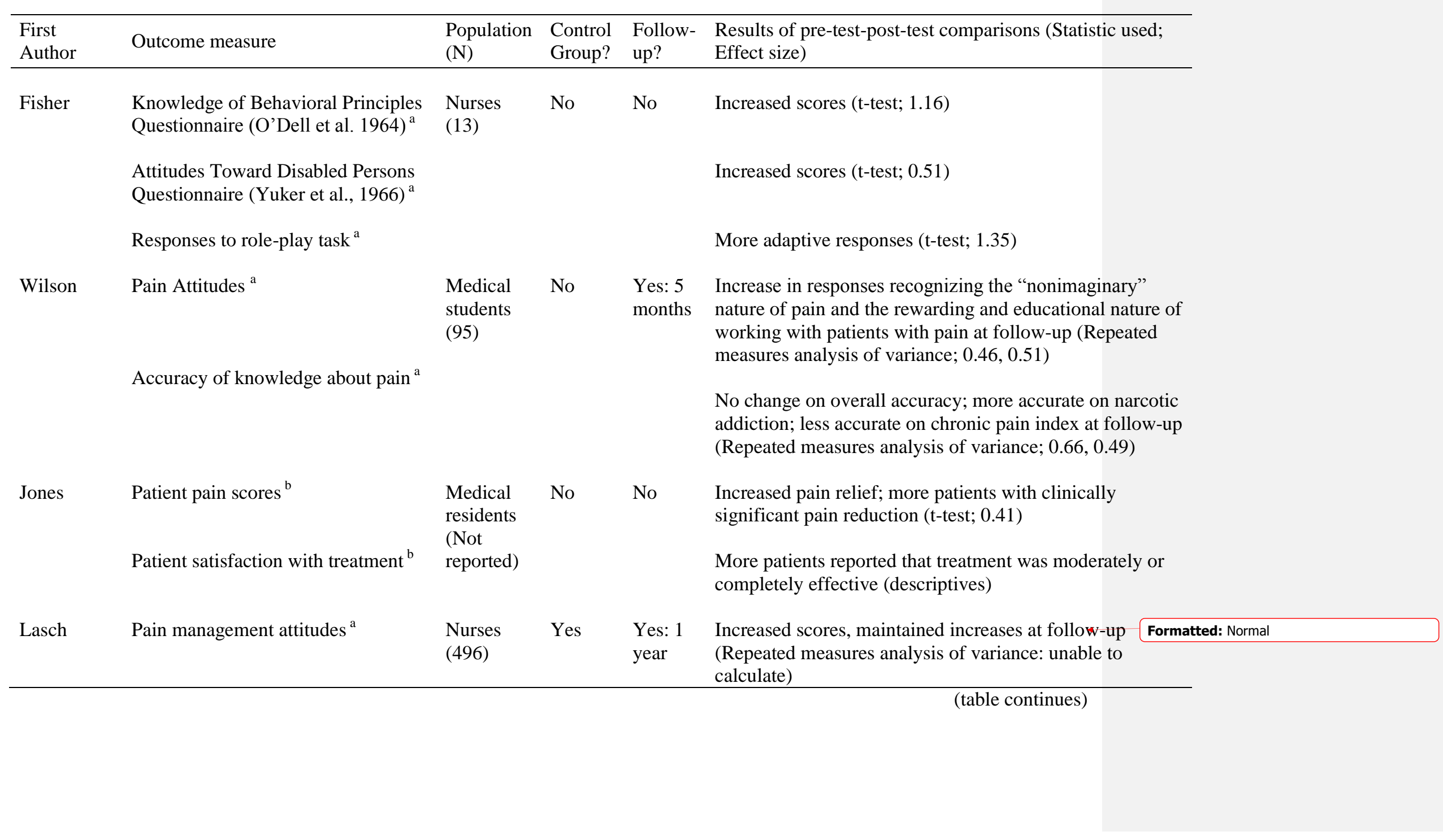


Table 2 (continued)

\begin{tabular}{|c|c|c|c|c|c|}
\hline $\begin{array}{l}\text { First } \\
\text { Author }\end{array}$ & Outcome measure & $\begin{array}{l}\text { Population } \\
(\mathrm{N})\end{array}$ & $\begin{array}{l}\text { Control } \\
\text { Group? }\end{array}$ & $\begin{array}{l}\text { Follow- } \\
\text { up? }\end{array}$ & $\begin{array}{l}\text { Results of pre-test-post-test comparisons (Statistic used; } \\
\text { Effect size) }\end{array}$ \\
\hline Lasch & $\begin{array}{l}\text { Pain management knowledge } \\
\text { Application of pain management }^{\text {knowledge }}{ }^{\mathrm{a}}\end{array}$ & $\begin{array}{l}\text { Nurses } \\
(496)\end{array}$ & Yes & $\begin{array}{l}\text { Yes: } 1 \\
\text { year }\end{array}$ & $\begin{array}{l}\text { Increased scores, maintained at follow-up (Repeated } \\
\text { measures analysis of variance: unable to calculate) } \\
\text { Increased scores, maintained at follow-up (Repeated } \\
\text { measures analysis of variance: unable to calculate) }\end{array}$ \\
\hline Ferrell & $\begin{array}{l}\text { Pain and pain management } \\
\text { knowledge and attitudes }{ }^{a}\end{array}$ & $\begin{array}{l}\text { Nurses } \\
(26)\end{array}$ & No & No & Increased scores (Descriptives) \\
\hline \multirow[t]{3}{*}{ Francke } & $\begin{array}{l}\text { Attitudes toward pain management } \\
\text { strategies }^{\text {a }}\end{array}$ & $\begin{array}{l}\text { Nurses } \\
(106)\end{array}$ & Yes & $\begin{array}{l}\text { Yes: } 6 \\
\text { months }\end{array}$ & $\begin{array}{l}\text { Increased scores on relaxation (Multiple analysis of } \\
\text { covariance; } 0.47 \text { ), no change on other psychosocial } \\
\text { interventions }\end{array}$ \\
\hline & $\begin{array}{l}\text { Number of psychosocial techniques } \\
\text { used }^{\text {a }}\end{array}$ & & & & $\begin{array}{l}\text { No change in number of techniques used (Multiple } \\
\text { analysis of covariance) }\end{array}$ \\
\hline & $\begin{array}{l}\text { Quality of psychosocial techniques } \\
\text { used }^{\text {a }}\end{array}$ & & & & \\
\hline Breitbart & $\begin{array}{l}\text { Pain and pain management } \\
\text { knowledge }^{\mathrm{a}}\end{array}$ & $\begin{array}{l}\text { Various } \\
\text { healthcare } \\
\text { profession } \\
\text { als (152) }\end{array}$ & No & No & $\begin{array}{l}\text { Higher quality reported (Multiple analysis of covariance; } \\
1.37 \text { ) } \\
\text { Increased scores (t-test; } 0.54)\end{array}$ \\
\hline \multirow[t]{2}{*}{ Zaza } & $\begin{array}{l}\text { Perceptions of pain management } \\
\text { techniques }^{\text {a }}\end{array}$ & $\begin{array}{l}\text { Various } \\
\text { healthcare } \\
\text { profession }\end{array}$ & No & $\begin{array}{l}\text { Yes: } 3 \\
\text { months }\end{array}$ & $\begin{array}{l}\text { Most participants reported "no change" in perceptions at } \\
\text { follow-up (descriptives) }\end{array}$ \\
\hline & $\begin{array}{l}\text { Familiarity with pain management } \\
\text { techniques }^{\text {a }}\end{array}$ & als (89) & & & $\begin{array}{l}\text { More familiar with massage therapy and therapeutic touch } \\
\text { (chi-square; } 0.51,0.89 \text { ), no change on familiarity with } \\
\text { acupuncture, hypnosis, and biofeedback at follow-up }\end{array}$ \\
\hline
\end{tabular}


Table 2 (continued)

\begin{tabular}{|c|c|c|c|c|c|}
\hline $\begin{array}{l}\text { First } \\
\text { Author }\end{array}$ & Outcome measure & $\begin{array}{l}\text { Population } \\
(\mathrm{N})\end{array}$ & $\begin{array}{l}\text { Control } \\
\text { Group? }\end{array}$ & $\begin{array}{l}\text { Follow- } \\
\text { up? }\end{array}$ & $\begin{array}{l}\text { Results of pre-test-post-test comparisons (Statistic used: } \\
\text { Effect size) }\end{array}$ \\
\hline \multirow[t]{2}{*}{ Brown } & $\begin{array}{l}\text { Pain and pain management } \\
\text { knowledge and attitudes }{ }^{\text {a }}\end{array}$ & $\begin{array}{l}\text { Hospital } \\
\text { staff (Not } \\
\text { reported) }\end{array}$ & No & No & Increased scores (unknown, p-value reported) \\
\hline & Pain documentation $^{\mathrm{c}}$ & & & & $\begin{array}{l}\text { More documentation of: use of self-report pain assessment } \\
\text { instrument, patient/family teaching about pain, and use of } \\
\text { non-pharmacological strategies (unknown, p-value } \\
\text { reported) }\end{array}$ \\
\hline Knoblauch & Analgesic administration $^{c}$ & $\begin{array}{l}\text { Nurses } \\
(52)\end{array}$ & No & No & $\begin{array}{l}\text { Longer time before first patient analgesic dose (analysis } \\
\text { of variance: unable to calculate), longer time between } \\
\text { doses of analgesic (t-test; } 0.51 \text { ) }\end{array}$ \\
\hline \multirow[t]{2}{*}{ Solomon } & Knowledge $^{\mathrm{a}}$ & $\begin{array}{l}\text { Various } \\
\text { healthcare }\end{array}$ & No & No & Increased scores (t-test; 1.77 ) \\
\hline & $\begin{array}{l}\text { Skill acquisition "Pain Control } \\
\text { Technique Checklist"d }\end{array}$ & $\begin{array}{l}\text { profession } \\
\text { als }(43)\end{array}$ & & & $\begin{array}{l}\text { No pre-post comparisons conducted, } 95.3 \% \text { of } \\
\text { participants demonstrated "high levels of skill" } \\
\text { (descriptives) }\end{array}$ \\
\hline \multirow[t]{2}{*}{ Pederson } & $\begin{array}{l}\text { Knowledge of deep breathing, } \\
\text { relaxation, distraction, imagery, and } \\
\text { cognitive restructuring }^{\text {a }}\end{array}$ & $\begin{array}{l}\text { Nurses } \\
(54)\end{array}$ & Yes & No & $\begin{array}{l}\text { Increased scores on all techniques (t-tests: average effect } \\
\text { size }=1.19 \text { ) }\end{array}$ \\
\hline & $\begin{array}{l}\text { Comfort with of deep breathing, } \\
\text { relaxation, distraction, imagery, and } \\
\text { cognitive restructuring }^{\text {a }}\end{array}$ & & & & $\begin{array}{l}\text { Increased scores on deep breathing, relaxation, imagery, } \\
\text { and cognitive restructuring, No change on distraction }(\mathrm{t}- \\
\text { tests: average effect size }=0.71)\end{array}$ \\
\hline
\end{tabular}

